\title{
Assigning Weights for Modified Project Quarter Back Rating Based Construction Project Performance Model
}

\author{
Prachi Vinod Ingle*, Gangadhar Mahesh \\ Department of Civil Engineering \\ National Institute of Technology Karnataka, Surathkal, India \\ *Corresponding author: prachi03ingle@ gmail.com
}

(Received February 18, 2019; Accepted April 22, 2019)

\begin{abstract}
The Indian construction industry is facing challenges due to performance shortfalls. The construction projects are highly complex, distinctive, fragmented and do not have of well-established performance assessment models to evaluate their project success. Assessing overall project success is not possible to measure by single factor. To address this limitation, the Modified Project Quarter Back Rating (PQR) model was developed for the Indian construction industry. Modified PQR model's output is a project score based on performance areas affecting project success and outcome. The model integrates ten performance areas that have identified through literature review. Performance areas included in the model are; (i) Cost (ii) Schedule (iii) Stakeholder satisfaction (iv) Safety (v) Quality (vi) Finance (vii) Environment (viii) Communication and collaboration (ix) Customer relation and (x) Productivity. These performance areas are measured through different performance metrics; i.e. performance metrics scores are aggregated to compute performance area scores. The model gives a single score that will help in comparing overall performance for different projects. This paper attempted to highlight the importance of performance metrics in modified Project Quarter Back Rating (PQR) based construction project performance assessment model for the Indian construction industry. The validity of the model needs assigning appropriate weights to the performance metrics as the weightage determines the relevance. Appropriate weights were determined using two round Delphi survey with 12 experts. Findings reveal that two performance metrics; return business from customer relation and OSHA recordable from safety have high weights. This modified PQR model will help key participants of the industry to compare the performance of various projects and to monitor performance areas that impact project performance rating.
\end{abstract}

Keywords- Project performance, Project success, Project scores, Modified PQR model, Delphi technique.

\section{Introduction}

The success of any construction project can be achieved by assessing project performance areas. The performance areas are considered important to monitor the project and need to ensure project objectives. There is a need to understand performance areas that influence project success. Traditionally performance areas i.e. cost, time, quality and meeting technical requirements were exclusively pursued the project success (Bourne et al., 2000). Various studies have considered project success as complex and encompass many other areas (Shenhar et al., 2001; Jugdev and Muller, 2005). In spite of several attempts to define project success, many studies concluded that project fails and do not achieve their objectives (Papke-Shield et al., 2010; Cicmil and Hodgson, 2006). Therefore, there is an enduring need to identify the performance areas that influence project success positively. Majority of researchers have focused on identifying performance areas to measure project success. However, these studies focused on comparing construction projects based on one or multiple performance areas but no attempt on combining all areas to get a single score. Various studies examine the definition of 'project success. Despite of similarity in literature, there is no accord among researchers for a comprehensive measure of project performance. The main reason is that each project has different priorities and project goals. Subsequent research has attempted to develop project performance models that can evaluate 
International Journal of Mathematical, Engineering and Management Sciences

Vol. 4, No. 4, 895-904, 2019

https://dx.doi.org/10.33889/IJMEMS.2019.4.4-071

project success such as The Balanced Scorecard; EFQM 2005; performance prism etc. Some models use subjective evaluation of performance areas based on expert's opinion and experience thus limiting its validity (Liu et al. 2014). It is also tedious to develop a standard model that consider all performance areas which determine the impact of each of their area on project success (Yong and Mustafa, 2013; Hanna et al., 2014). Recently, Hanna et al., (2014) and El Asmar et al., (2015) developed rating method which based on weighted average of key sports performance metrics to compare quarterback. This Quarterback rating is calculated by adding individual scores of Total Passing Yards, Quarterback Pass Attempts, Completed Touchdown Passes, Total Interceptions and Quarterback Pass Completions. This was consolidated to a single score that can be used to compare the performance of players. In this regard, Project Quarterback Rating (PQR) is an approach to evaluate the performance of construction projects (El Asmar et al., 2015). This rating model combines seven areas namely, customer relations, communication, schedule, profit, safety, quality and cost and leads to a single score which is utilized to compare the performance of construction projects. This study is limited to the Integrated Project Delivery system and hence needs modification to suit other type of construction projects.

Considering that performance priorities are contextualized in nature, this paper focuses on the adaptation of $\mathrm{PQR}$ model in the Indian construction industry. Hence, there is a need to contextualize PQR model to reflect performance areas for the Indian construction industry. Therefore, the word modified Project quarterback rating (PQR) is adopted. This paper presents a modified PQR model to assess the performance of construction projects in terms of ten performance areas consisting of: Cost (C), Schedule (S), Stakeholder satisfaction (St), Safety $(\mathrm{Sa})$, Quality (Q), Finance (F), Environment (E), Communication and Collaboration (Co), Customer relation $(\mathrm{Cu})$ and Productivity $(\mathrm{Pr})$ and 28 performance metrics related to their project performance areas. The main objective of this paper is to assign appropriate weights for performance metrics that combine their performance areas in the modified PQR Model.

\section{Research Method}

An extensive review of the literature was conducted and a detailed list of performance areas was prepared. Taking effectiveness and suitability into consideration the suggestions given by industry professionals on the Indian construction industry, the performance areas and metrics were finalized. In this regard, a questionnaire-based survey was used to evaluate performance areas suitable for Indian construction projects. Following this, the Delphi technique is used to allocate weights for performance metrics in the modified PQR Model.

\subsection{Delphi Technique}

Delphi method is a qualitative research method in which the survey instrument is used to provide answers with the opinion of experts. According to Scholl et al. (2004), Delphi technique can be used when there is less information available about a topic. The Delphi technique is widely used and accepted in various field of construction management such as safety, cost, schedule (Hallowell and Gambatese 2009; Dawood and Sikka, 2009; Ke et al., 2010, Lin et al., 2011), quality management (Heras Saizarbitoria, 2006; Papic et al., 2017), GIS (Hatzichristos and Giaoutzi, 2006), labour issues (Shapira and Lyachin, 2009), risk management (Perera et al., 2014) etc to achieve convergence of views through the experts panel. The consensus is achieved through several rounds of expert's opinion. 
International Journal of Mathematical, Engineering and Management Sciences

Vol. 4, No. 4, 895-904, 2019

https://dx.doi.org/10.33889/IJMEMS.2019.4.4-071

\subsection{Questionnaire Development}

A survey instrument was developed to gather responses from professionals in the construction industry. There are various methods used for assigning weights for factors. The most common method is the 100-point method, which was used and it consists of 100 points should be distributed among each performance criteria's (Nijkamp et al., 1990). The respondents were requested to assign weights to performance metrics in order to reflect the impact on specific performance area and is expressed on percentage. In order to validate survey content validity was used to check whether the performance area covers all performance metrics (Hair et al., 2010). The questionnaire was independently evaluated by 3 academic experts, 2 research experts and 2 industry experts for content validity. After content validity, the questionnaire was refined by experts' opinion for assigning weights using the Delphi technique. Sampling frame consists of project managers, academicians and industry experts from were identified for adopting this technique. There is no exact sample size calculation for the Delphi technique (Skulmoski, 2007). The approach is based on open-ended questions to which experts were asked to answer.

Numerous studies have used two to three rounds to reach stable result to achieve the level of consensus. In this study, two rounds of the Delphi survey were conducted. The experts involved in the survey were having professional experience of 10 years in the industry and having sound knowledge in construction management practices. Initially, 20 experts were willing to participate in the study. All 20 members were contacted via email. Descriptive statistics were analyzed for mean of performance metrics was analyzed for both rounds and weights were finalized. An average of 4-6 weeks was required to collect and data for both round of Delphi questionnaire. The data was analyzed and presented as final summary of assigned weights. The flowchart of survey activities is shown as Figure 1.

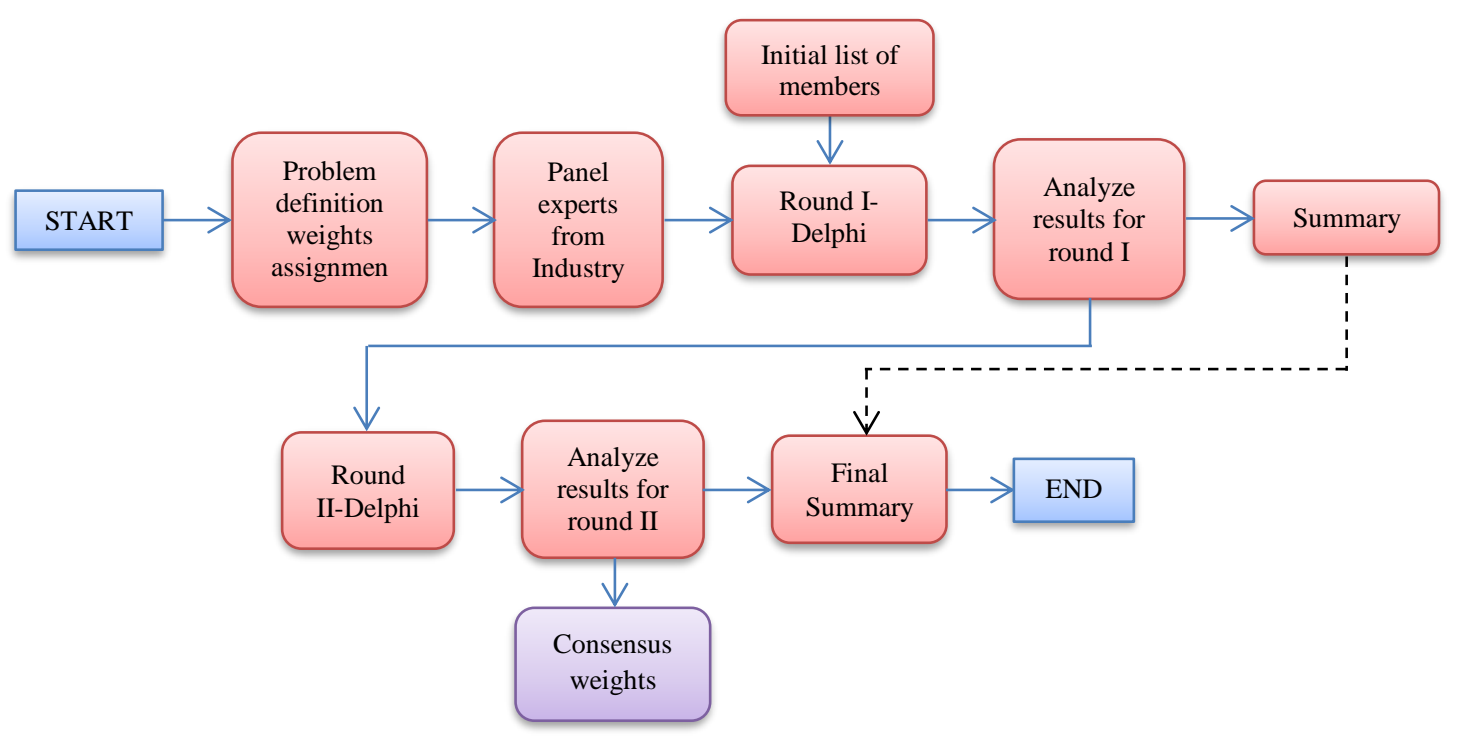

Figure 1. Flowchart of survey 
International Journal of Mathematical, Engineering and Management Sciences

Vol. 4, No. 4, 895-904, 2019

https://dx.doi.org/10.33889/IJMEMS.2019.4.4-071

\section{Data Analysis}

\subsection{Modified PQR Model Formulation for Indian Construction Industry}

Modified PQR Model approach combines ten performance areas. For the purpose of formulation of $\mathrm{PQR}_{j}$ model, weighted average formula of different performance areas $\left(A_{i j}\right)$ was used as shown in Equation (1)

$$
P Q R_{j}=\sum_{i=1}^{I} W_{i} A_{i j}
$$

where, $\mathrm{Wi}=$ weightage of performance area ' $\mathrm{i}$ '; $I=10$;

$=1,2,3 \ldots \ldots 10$ as there are 10 performance areas

$J=1,2,3 \ldots \ldots$ as there are ' $\mathrm{n}$ ' respondents.

$A_{i j}=$ score of project $j$ for performance area $i$.

Figure 2 shows the detailed structure of the modified PQR model. Tier I represent the single PQR score, Tier II represent ten performance areas $\left(A_{i j}\right)$ and Tier III represent components which combine these ten performance areas which is indicated as performance metrics $\left(M_{i j k}\right)$. The overall project performance rating $P Q R_{j}$ depends on performance areas $i$. The performance scores $A_{i j}$ for each of the ten areas also integrate many performance metrics $M_{i j k}$ as shown in Figure 2. For example, Schedule performance area is combination of three performance metrics construction speed, schedule payment, and schedule growth. The project score achieved by performance metrics is represented as ' $M_{i j k}$ ' where ' $k_{i}$ ' is 3, representing number of metrics that combine schedule performance area ' $i$ '. If $i$ represent schedule performance area then ' $A_{i j}$ ' represents project score for schedule area. $A_{i j}$ combines of $M_{i j k}$. The mean value and standard deviation value were calculated for each performance metrics ' $k$ ' in each performance area ' $i$ '. The unit of measurement is different for each performance areas such as cost and quality hence there was a need for standardization to measure according to a standardized scale. For instance, quality performance area include four metrics with differents unit of measurement. Standardization shifts the mean value of the distribution to zero (El Asmar et al. 2015). In similar way, standardization for each project score ' $M_{i j}$ ' is standardized to ' $Z_{i j k}$ '. The modified PQR Model is shown in Figure 2.

The project score for each performance area is calculated as shown in Equation (2):

$$
A_{i j}=\sum_{k=1}^{k i} W_{i k} Z_{i j k}
$$

$W_{i k}=$ Weight of each performance metric within a specific performance area ' $i$ '. The $Z_{i j k}$ represents $Z$ scores. The ' $Z_{i j k}$ ' are centered on zero and consists of positive and negative values. The assigned weights were obtained from the Delphi technique. The assigned weights will highlight the importance of performance metrics within specific area. Details about Delphi technique will be explained in the later section.

' $Z$ ' scores are calculated using Equation (3).

$Z_{i j k}=\left(x_{i j k}-\mu_{i k}\right) / \sigma_{i k}$ 
International Journal of Mathematical, Engineering and Management Sciences

Vol. 4, No. 4, 895-904, 2019

https://dx.doi.org/10.33889/IJMEMS.2019.4.4-071

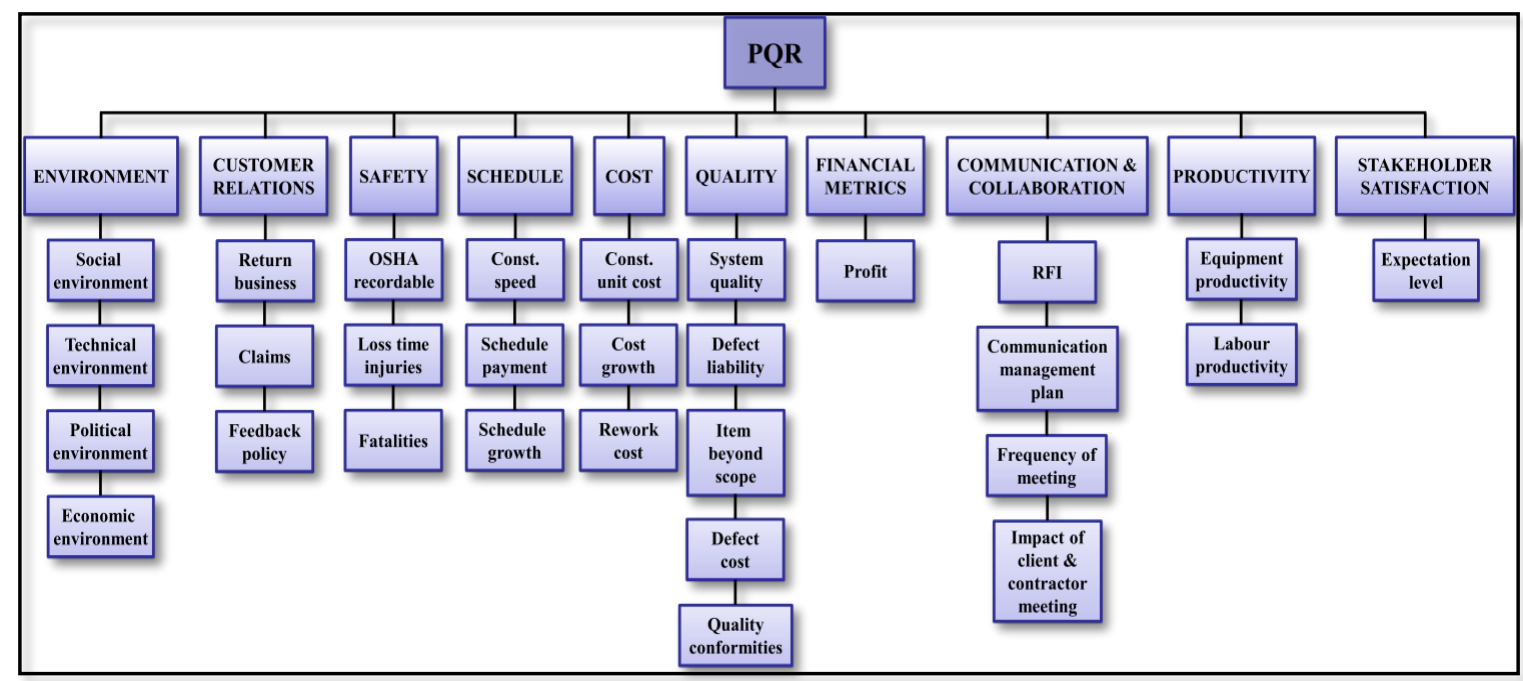

Figure 2. Modified PQR Model

In Equation (2) and Equation (3), the normalization method is used to standardize ' $A_{i j}$ ' scores. The $x_{i j k}$ denotes original performance metrics scores. $\mu_{i k}$ and $\sigma_{i k}$ are mean and standard deviation of the performance metrics. The mean of altogether $A_{i j}$ is zero, $A_{i j}$ is divided by overall standard deviation of $A_{i j}$. The final $A_{i j}$ result can be interpreted that a positive value represents above average performance and a negative value represents below average performance and zero indicates average performance. Lastly, the standardized project scores for performance area are combined into Equation (1).

\subsection{Modified PQR Formula}

The weighted average scores for ten performance areas were calculated from the survey. Weights of all performance areas are calculated as shown in Equation (4)

Weights of Performance areas $=\left[\frac{F_{P A}}{\sum_{P A=0}^{10} F_{P A}}\right] * 100$

$\mathrm{F}_{\mathrm{PA}}=$ Frequency of each performance areas.

$\sum_{P A=0}^{10} F_{P A}=$ Sum of all frequencies of performance area.

Performance Areas Scores (PAS) for all performance areas (C, S, St, Sa, Q, F, E, Co, Cu, and Pr) were calculated as shown in Equation (5). The weights $\left(W t_{A S I}, W t_{A S 2} \ldots . . . W t_{A S N}\right)$ for 28 performance metrics were calculated using Delphi study.

$P A S=\frac{W t_{A S 1} *\left(\frac{P M_{1}-M 1}{S D 1}\right)+W t_{A S 2} *\left(\frac{P M_{2}-M 2}{S D 2}\right)+\cdots \ldots \ldots \ldots t_{A S N} *\left(\frac{P M_{n}-M n}{S D n}\right)}{S D}$

$\mathrm{Wt}_{\mathrm{AS} 1}=$ Weightages assigned for first performance metrics in a specific area by Delphi method. 
International Journal of Mathematical, Engineering and Management Sciences

Vol. 4, No. 4, 895-904, 2019

https://dx.doi.org/10.33889/IJMEMS.2019.4.4-071

$\mathrm{Wt}_{\mathrm{AS} 2}=$ Weightages assigned for second performance metrics in a specific area by Delphi method.

$\mathrm{PM}_{1}=$ First Performance metric in that specific performance areas.

$\mathrm{PM}_{2}=$ Second Performance metrics in that specific performance areas.

$\mathrm{M}_{1}=$ Mean score of first performance metrics in a specific area.

$\mathrm{M}_{2}=$ Mean score of second performance metrics in a specific area.

$\mathrm{SD}_{1}=$ Standard deviation score for first performance metrics in the area.

$\mathrm{SD}_{2}=$ Standard deviation score for second performance metrics in the area.

$\mathrm{SD}=$ Overall standard deviation score for specific performance area.

$\mathrm{PM}_{1}, \mathrm{PM}_{2} \ldots \mathrm{PMn}$ will be calculated using measurement scale of that specific performance metrics.

Similarly, project scores for different performance areas can be calculated and used in modified PQR Equation (5).

The weight coefficient of performance areas here is calculated and is used in the modified PQR formula as shown below in Equation (6).

$$
P Q R=\frac{\begin{array}{c}
W_{C} * C+W_{S} * S+W_{S t} * S t+W_{S a} * S a+W_{Q} * Q \\
+W_{F} * F+W_{E} * E+W_{C o} * C o+W_{C u} * C u+W_{P r} * P r
\end{array}}{S D}
$$

The denominator value is the overall standard deviation for all project scores. The weights established for ten performance areas are indicated as $W_{c}, W_{S}, W_{S t}, W_{S a}, W_{Q}, W_{F}$, $W_{E}, W_{C o}, W_{C u}$, and $W_{P r}$, and calculated using Equation (2). The weights for performance metrics calculated with the Delphi technique will be discussed in the forthcoming section.

\subsection{Delphi Round -I}

The Round-I of the Delphi questionnaire was a structured questionnaire for collecting weights of performance metrics in specific performance areas. In the survey, respondents were asked to provide weights in percentages $(0-100 \%)$ for performance metrics to represent the impact of project performance in the construction industry. These weights represent the importance of each performance metrics to the corresponding performance area. A detailed description about the survey is provided to the respondent before conducting round -I of Delphi survey. Round one was completed by 12 people with a response rate of $60 \%$. The profile of experts for the Delphi group is highlighted in Table 1.

Table 1. Demographic profile of expert

\begin{tabular}{|c|c|c|}
\hline Projects & Number of experts & Experience(years) \\
\hline Infrastructure & 4 & $10-15$ \\
\hline Commercial & 2 & $10-12$ \\
\hline Residential & 2 & $10-11$ \\
\hline Academicians & 4 & $25-40$ \\
\hline
\end{tabular}


International Journal of Mathematical, Engineering and Management Sciences

Vol. 4, No. 4, 895-904, 2019

https://dx.doi.org/10.33889/IJMEMS.2019.4.4-071

Respondents were asked to send response within 20 days. The responses received were summarized and analyzed to obtain the levels of consensus. The mean score value is calculated to indicate the level of consensus from Delphi round- I (Singh and Singh, 2017).

\subsection{Delphi Round-II}

Delphi round II was conducted after five weeks from round one. In the second round of Delphi study, the results from the first round were presented to the respondents and were asked to modify the weights if necessary. The respondents were allotted a time period of 15-20 days to submit their responses. Round II was completed with the same response rate of $60 \%$. All responses were then analyzed collectively. The results obtained have been summarized in results and discussions. Comparison of the results of the round I and II showed a slight change in responses.

\section{Result and Discussion}

The study of focuses on determining the weights of the round I and II obtained from Delphi survey. These are summarized has represented in Figure 3. Cost performance area covers Construction Unit Cost (CUC), Cost Growth (CG) and Reworks Cost (RC). CUC has the highest weight $(51 \%)$ in comparison with the remaining metrics RG $(25 \%)$ and CG (24\%). This is because CUC explains direct and indirect cost in the project and slight deviation or change in this will significantly impact the performance of the project. In the schedule performance area, Delphi experts assigned $48 \%, 28 \%$ and $24 \%$ weights to Construction Speed (CS), Schedule Payment (SP), and Schedule Growth (SC) respectively. CS was given the highest weight compare to SP and SC. SP and SC show that they are almost equally important for the progress of work. The schedule performance area is used to assess to use how project monitor to the planned schedule. Safety performance area includes OSHA (OS), Lost Time Injury (LTI) and Fatalities (F). Panel members assigned maximum weightage $(62 \%)$ for OSHA safety practices as it needs to be strictly followed on site. LTI and fatalities were assigned $21 \%$ and $17 \%$ respectively. Proper safety management practices should be taken care of the project team members to avoid accidents and miscellaneous cost. Project Quality (PQ), Defect Liability Period (DFP), Item beyond cost (IBC), and Defect Cost (DC) covered quality area. PQ was given highest weight $(55 \%)$ among the rest of the metrics. Poor performance with respect to quality will lead to rework and hence it should be monitored continuously for better project performance. The quality performance area in the construction industry helps to ensure that projects will achieve the requirements of as per quality standard. Environment area covers four metrics namely, Social (S), Technical (T), Political (P) and Economic (E) with the weight of $24 \%, 33 \%, 16 \%$, and $27 \%$ respectively. Environment performance area improves performance in economic and technical terms. 
International Journal of Mathematical, Engineering and Management Sciences

Vol. 4, No. 4, 895-904, 2019

https://dx.doi.org/10.33889/IJMEMS.2019.4.4-071

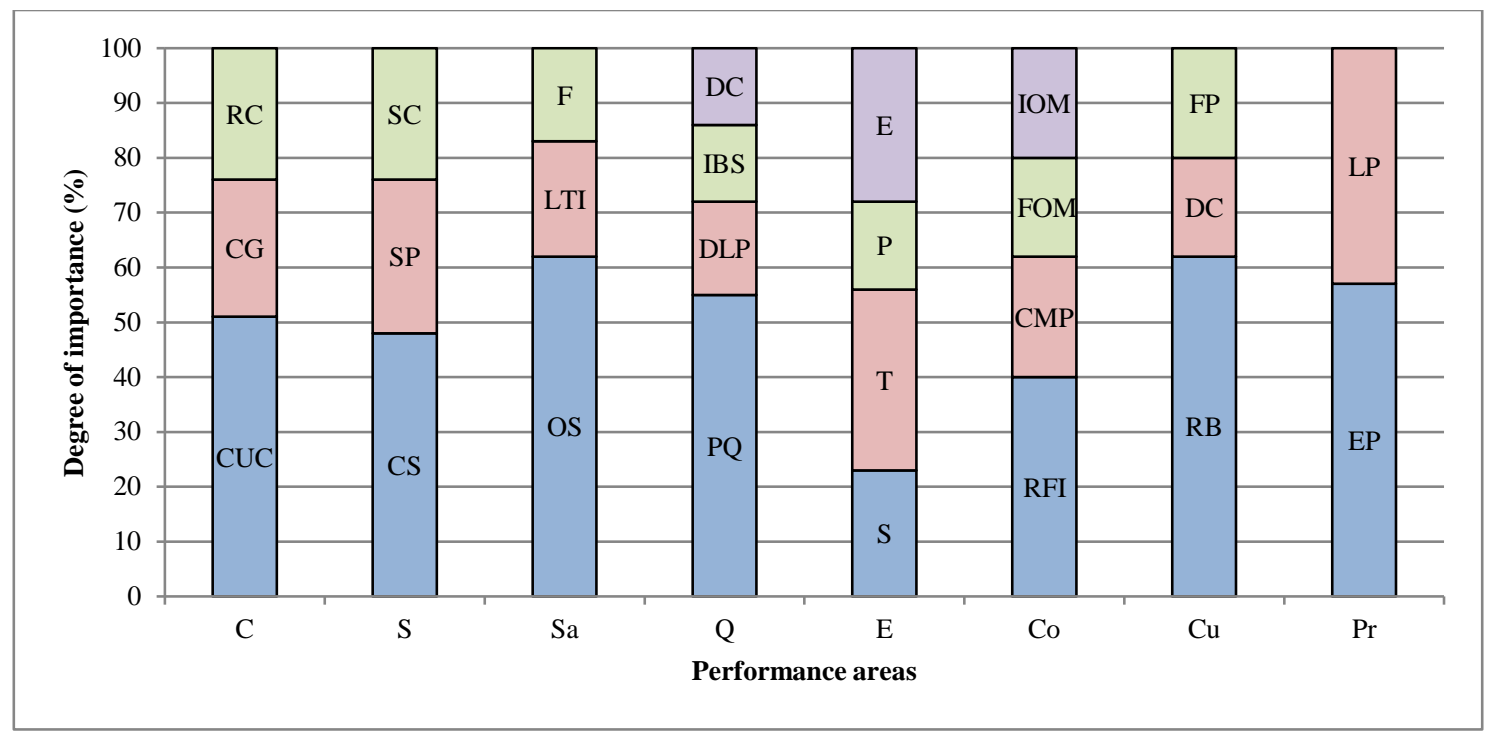

Figure 3. Weights for performance metrics

Communication and collaboration cover Request for information (RFI), Communication Management Plan (CMP), Frequency of Meeting (FOM), and Impact of meeting (IMP). RFI was assigned less weight of $40 \%$ as it is an important source of the project. CMP and IMP had the weight of $22 \%$ and $20 \%$ and less weight was for FOM (18\%). Proper communication is essential for successful construction projects. It will benefit to find ways to integrate and work together effectively. Among performance areas, Customer relation includes Return Business (RB), Dispute Claims (DC), and Feedback Policy (FP). RB (62\%) was found to be highly significant among all performance metrics as it led to higher prospective clients. DC was given less weightage (18\%) as it consumes time for project completion. Feedback policy was given slightly more weight $(20 \%)$ as it is significant in long-term improvement of project performance. Many stakeholders assess the performance of the project and understand the satisfaction requirement of the customers. The stakeholders track the satisfaction with feedback and their rating. Maintaining good customer relations with stakeholders will help to complete the project successfully. Equipment Productivity (EP) and Labour Productivity (LP) were given 57\% and 43\% importance in the productivity area. Poor productivity among other areas may have an impact on construction time and cost overruns. Rewards, incentives, levels of expectation, and the well-being of workers are some factors that influence the productivity of the construction industry that impact project performance. The weightages assigned to each of the performance metrics indicates the degree of importance in considering each metrics corresponding to performance areas.

\section{Conclusion}

The paper introduces construction based project performance assessment tool is modified PQR model to assess project success. In this assessment tool, weights are assigned to performance metrics and method to determine their weightages with Delphi technique is proposed. The modified PQR model can give new way to manage the business. It can be used in decision making for management. Hence this model assists key participants of the project to prioritize their efforts towards evaluating performance metrics in the specific areas. The Delphi expert panel resulted in identifying the importance of performance metrics in the Indian construction 
International Journal of Mathematical, Engineering and Management Sciences

Vol. 4, No. 4, 895-904, 2019

https://dx.doi.org/10.33889/IJMEMS.2019.4.4-071

project, which require a significant level of modified PQR Model. After analyzing weighting distribution results, Return business and OSHA recordable have obtained maximum importance and hence has the largest influence on project performance. IBC and DC have low importance. Furthermore, the panel members seem to recognize the importance of ignored performance metrics such as communication and collaboration, productivity and environment. In order to have successful projects, the professional experts have the arduous task of having best practice across the industry in the aspect of all key participants. While the data on which these findings are limited to specific geographic constraints. Future research can demonstrate the applicability of the modified PQR model with a case study.

\section{Conflict of Interest}

The authors confirm that there is no conflict of interest to declare for this publication.

\section{Acknowledgement}

The authors acknowledge and express the gratitude to the reviewer's constructive comments and valuable suggestion towards the improvement of the paper.

\section{References}

Bourne, M., Mills, J., Wilcox, M., Neely, A., \& Platts, K. (2000). Designing, implementing and updating performance measurement systems. International Journal of Operations \& Production Management, 20(7), 754-771.

Cicmil, S., \& Hodgson, D. (2006). New possibilities for project management theory: A critical engagement. Project Management Journal, 37(3), 111-122.

Dawood, N., \& Sikka, S. (2009). Development of 4D based performance indicators in construction industry. Engineering, Construction and Architectural Management, 16(5), 438-458.

El Asmar, M., Hanna, A.S., \& Loh, W.Y. (2015). Evaluating integrated project delivery using the project quarterback rating. Journal of Construction Engineering and Management, 142(1), 04015046.

Hair, J.F., Anderson, R.E., Babin, B.J., \& Black, W.C. (2010). Multivariate data analysis: a global perspective (Vol. 7). Pearson, Upper Saddle River, NJ

Hallowell, M.R., \& Gambatese, J.A. (2009). Activity-based safety risk quantification for concrete formwork construction. Journal of Construction Engineering and Management, 135(10), 990-998.

Hanna, A.S., Lotfallah, W., Aoun, D.G., \& Asmar, M.E. (2014). Mathematical formulation of the project quarterback rating: New framework to assess construction project performance. Journal of Construction Engineering and Management, 140(8), 04014033.

Hatzichristos, T., \& Giaoutzi, M. (2006). Landfill siting using GIS, fuzzy logic and the Delphi method. International Journal of Environmental Technology and Management, 6(1), 218-231.

Heras Saizarbitoria, I. (2006). How quality management models influence company results-conclusions of an empirical study based on the Delphi method. Total Quality Management \& Business Excellence, 17(6), 775-794

Jugdev, K., \& Müller, R. (2005). A retrospective look at our evolving understanding of project success. Project management journal, 36(4), 19-31. 
International Journal of Mathematical, Engineering and Management Sciences

Vol. 4, No. 4, 895-904, 2019

https://dx.doi.org/10.33889/IJMEMS.2019.4.4-071

Ke, Y., Wang, S., Chan, A.P., \& Lam, P.T. (2010). Preferred risk allocation in China's public-private partnership (PPP) projects. International Journal of Project Management, 28(5), 482-492.

Lin, L.K., Chang, C.C., \& Lin, Y.C. (2011). Structure development and performance evaluation of construction knowledge management system. Journal of Civil Engineering and Management, 17(2), 184-196.

Liu, J., Love, P.E., Davis, P.R., Smith, J., \& Regan, M. (2014). Conceptual framework for the performance measurement of public-private partnerships. Journal of Infrastructure Systems, 21(1), 04014023.

Nijkamp, P., Rietveld, P., \& Voogd, H. (1990). Multicriteria evaluation in physical planning, NorthHolland, Amsterdam.

Papic, L., Mladjenovic, M., Carrión García, A., \& Aggrawal, D. (2017). Significant factors of the successful lean six-sigma implementation. International Journal of Mathematical, Engineering and Management Sciences, 2(2), 85-109.

Papke-Shields, K.E., Beise, C., \& Quan, J. (2010). Do project managers practice what they preach, and does it matter to project success?. International Journal of Project Management, 28(7), 650-662.

Perera, B.A.K.S., Rameezdeen, R., Chileshe, N., \& Hosseini, M.R. (2014). Enhancing the effectiveness of risk management practices in Sri Lankan road construction projects: A Delphi approach. International Journal of Construction Management, 14(1), 1-14.

Scholl, W., König, C., Meyer, B., \& Heisig, P. (2004). The future of knowledge management: an international Delphi study. Journal of Knowledge Management, 8(2), 19-35.

Shapira, A., \& Lyachin, B. (2009). Identification and analysis of factors affecting safety on construction sites with tower cranes. Journal of Construction Engineering and Management, 135(1), 24-33.

Shenhar, A.J., Dvir, D., Levy, O., \& Maltz, A.C. (2001). Project success: a multidimensional strategic concept. Long Range Planning, 34(6), 699-725.

Singh, S., \& Singh, L. P. (2017) Occupational safety culture of workers at shop floor in medium scale iron and steel industries of Punjab state in India: development of safety index. Journal of Steel Structures \& Construction, 3(126), 1000126.

Skulmoski, G.J., Hartman, F.T., \& Krahn, J. (2007). The Delphi method for graduate research. Journal of Information Technology Education: Research, 6(1), 1-21.

Yong, Y.C., \& Mustaffa, N.E. (2013). Critical success factors for Malaysian construction projects: an empirical assessment. Construction Management and Economics, 31(9), 959-978. 